\title{
Long-Term Effect of Some Skin Moisturizers
}

\author{
Ørjan G. Martinsen ${ }^{*}$ and Sverre Grimnes \\ Department of Physics, University of Oslo, P.O. Box 1048 Blindern, N-0316 Oslo, Norway \\ Department of Clinical and Biomedical Engineering, Rikshospitalet, N-0027 Oslo, Norway
}

\begin{abstract}
The long term moisturizing effect of ten different skin care products was tested on 22 female volunteers using a low frequency electrical bioimpedance instrument. We found large differences in the moisturizing effect between different products and also large interpersonal variations. Products which gave a large increase in skin hydration on one person could have no effect on another person. These results suggest that there are differences in skin types and that one particular formulation with a given mode of action may be ideal for one skin type but inappropriate for another.
\end{abstract}

\section{INTRODUCTION}

Water is essential to skin function and the degree of hydration is closely linked to the vital plasticity and barrier function of the skin $[1,2]$. For this and other reasons, a great majority of adult women apply moisturizers to their skin on a daily basis. The word "moisturizer" is perhaps as difficult to define as the concept of "dry skin" [3], but an abundance of different products commonly referred to as "skin moisturizers", are nevertheless constantly promoted on the cosmetic market. The moisturizing effect of most of these products is unpublished, however, mostly because of lack of appropriate instrumentation. In this paper we present the results from a study of 10 different moisturizers where a well documented scientific method for skin hydration assessment has been utilized. The study showed that there are significant differences in the effect of different products and furthermore that there are also substantial interpersonal differences in the effects.

\section{MATERIALS AND METHODS}

Ten different skin moisturizers were acquired from local pharmacies and beauty parlors. Without giving any other information, we asked each time for a "good skin moisturizer" and purchased the product that was recommended to us. The first ten different products were then tested on a total of 22 female volunteering students from our university. Their age was $22 \pm 3$ years and the study was carried out in March with an ambient relative humidity in the laboratory of $10-15 \%$ and a temperature of $21-23^{\circ} \mathrm{C}$. Subjects with a history of skin disease or with atopic skin were excluded from the study. The products are later in this paper consecutively labeled from 1 to 10 , and the label 100 is used for a nontreated reference area. All products were facial creams except for product 3 and 4, which were body lotions.

Each volunteer used five different skin moisturizers, which means that each product was tested on eleven test subjects. The testing period lasted for three weeks where week

*Address correspondence to this author at the Department of Physics, University of Oslo, P.O. Box 1048 Blindern, N-0316 Oslo, Norway; Tel: +47 22856474; Fax: +47 22856422; E-mail: o.g.martinsen@fys.uio.no one was a washout period where the volunteers were asked not to use any moisturizing agents or other formulations on their arms. They were furthermore asked not to wear wristwatches or bracelets during the three-week period. In week two, the volunteers applied $0.1 \mathrm{~mL}$ of each moisturizer to a marked test area on the volar side of their forearm, twice a day (at about 10 a.m. and 10 p.m.) for seven days. The moisturizers were applied from syringes in order to control the amount used, and the products were gently massaged into the stratum corneum. Three $27 \mathrm{~cm}^{2}$ large areas were marked on each forearm of the volunteers, thus allowing five different products to be tested along with one non-treated reference area. The anatomical testing site for each product was systematically varied between the volunteers to reduce influence from differences in skin properties.

Measurement of the degree of stratum corneum hydration was performed as low frequency electrical admittance measurements. This approach has earlier been found suitable for the assessment of skin hydration [4-9], and an instrument based on low frequency electrical susceptance measurements has been described and compared with other methods in previous articles (see e.g. [10]). The instrument uses low frequency, which ensures that the measurements are focused on the stratum corneum only $[11,12]$. Furthermore, measuring only the susceptance and not the conductance eliminates any contribution from sweat duct filling [13]. Measurements are done by pressing a spring-loaded probe against the skin and then reading the measured susceptance value that is displayed on the instrument after 4 seconds. The measurement current is very low and typically in the nanoampere range and is hence not percepted by the test subject.

Measurements were carried out each morning for five days (Monday through Friday) in week two and five days (Monday through Friday) in week three. In week two the moisturizers were applied after the measurements and no effect of less than 12 hours duration could consequently be detected in this study. The volunteers always stabilized in the laboratory for at least $15 \mathrm{~min}$ with uncovered underarms before any measurements were carried out. We always made three consecutive measurements on adjacent locations on each test area, and in the subsequent statistical analysis of the measured data we used the logarithm of the values in 
order to meet the criteria for normality. Using the logarithm of the measured susceptance also makes the scale proportional to the absolute water content of the stratum corneum [9].

\section{RESULTS}

A two-way ANOVA (factors = product and day) was performed on the logarithm of the measured data, and the results are presented graphically in Figs. (1) and (2).

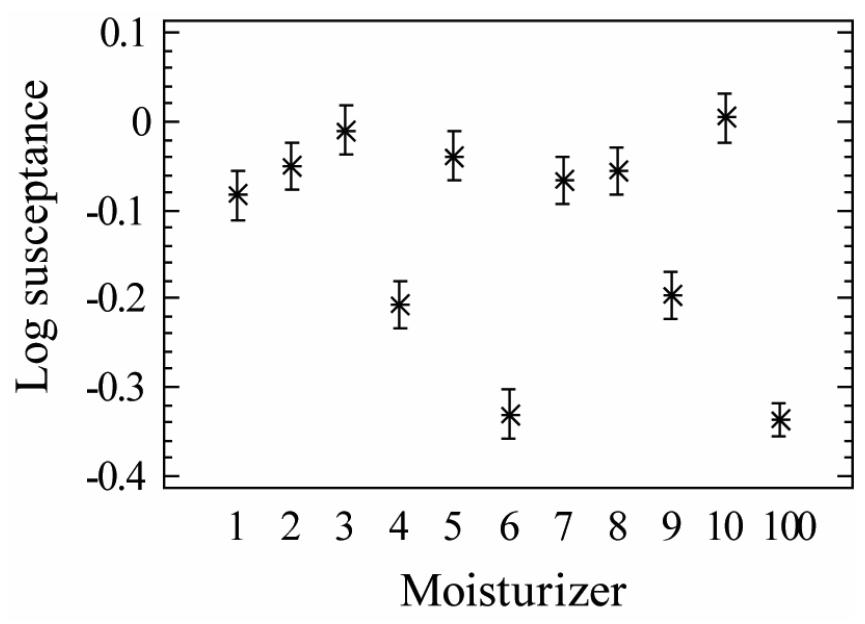

Fig. (1). Result of two-way ANOVA showing moisture level for products 1-10 and non-treated reference site (marked 100). Stars are mean values for all measured days and bars show $95 \%$ confidence level. The vertical axis is in log of measured surface susceptance density $\left[\mu \mathrm{S} / \mathrm{cm}^{2}\right]$.

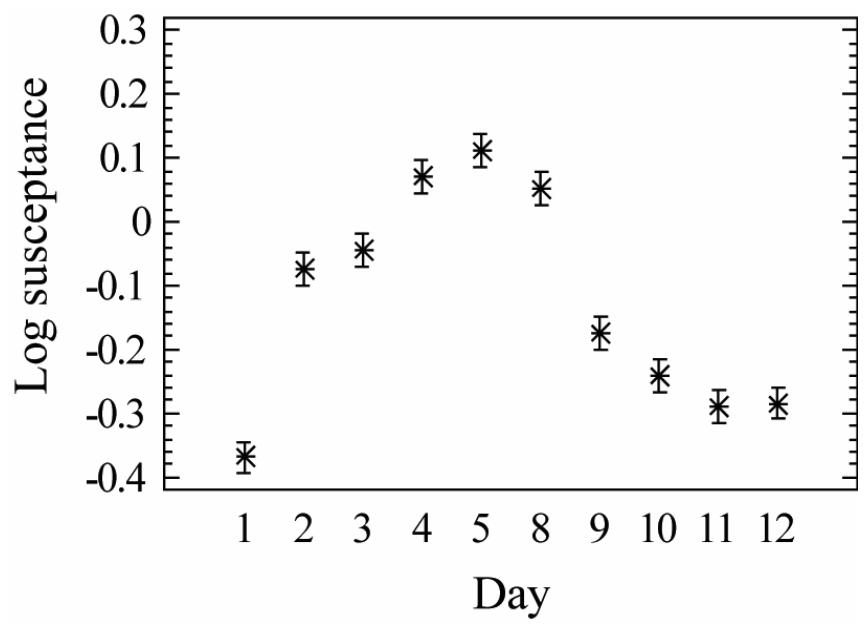

Fig. (2). Result of two-way ANOVA showing moisture level for first five days of week two (marked 1-5) and first five days of week three (marked 8-12). Stars are mean values for all products and bars show $95 \%$ confidence level. The vertical axis is in log of measured surface susceptance density $\left[\mu \mathrm{S} / \mathrm{cm}^{2}\right]$.

Fig. (1) shows that the products are different in their ability to induce increased hydration of the stratum corneum. The average hydration on skin sites treated with product 6 is not significantly different from a non-treated site (marked 100). The rest of the products give significant increase in hydration, but the increase is lower for products 4 and 9 than for the rest. Fig. (2) shows that there is an accumulative effect of treatment twice a day, reaching a peak value after typically four days. After interrupting the treatment, moisture levels return to previous values after roughly four days, i.e. about the same time required for full effect to build up. We found considerable individual differences in the effects of the different products. This is illustrated in Fig. (3) where results from six test subjects have been plotted. Fig. (3) shows how much the moisture level has increased from day 1 (before any treatment) to day 5 for all 10 products.

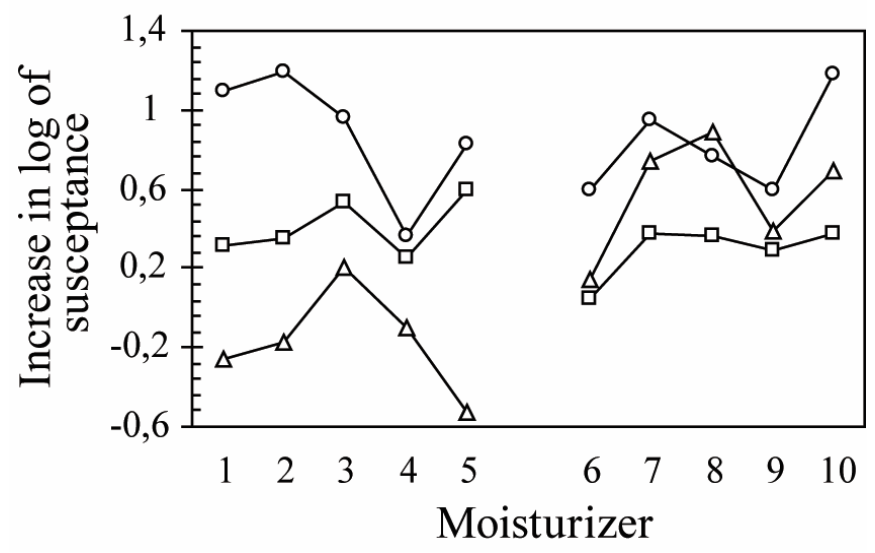

Fig. (3). Increase in hydration level measured on day 5 as compared to day 1 (before any treatment) for six of the test subjects. Products are marked 1-10 and the vertical axis is the increase in log of measured surface susceptance density $\left[\mu \mathrm{S} / \mathrm{cm}^{2}\right]$.

Assessing the moisturizing effect by subtracting the base line has earlier been found more correct than e.g. presenting the relative increase by division by the base line [10]. For example, Fig. (3) shows that product 5 gives the lowest hydration value of all products on one test person, whereas it produces the best effect of all products on another person.

\section{DISCUSSION}

This study shows that there are significant differences between the effects of different skin moisturizers. Of the two body lotions included in the study, one of them showed a long-term effect comparable to the most efficient facial creams, whereas the other had a significantly lower effect than most of the facial creams. There were also large differences between the test subjects when ranking the products on the basis of moisturizing effects. This suggests that there are differences in skin types and that one particular formulation with a given mode of action may be ideal for one skin type but inappropriate for another. This calls for a more individual assessment of the skin of customers, preferably with measurements revealing the best category of products for each person.

\section{REFERENCES}

[1] Blank IH. Factors which influence the water content of the stratum corneum. J Invest Dermatol 1952; 18: 433-40.

[2] Blank IH. Further observations on factors which influence the water content of the stratum corneum. J Invest Dermatol 1953; 21: 259-71.

[3] Lodén M, Maibach HI. Dry skin and moisturizers - chemistry and function. CRC Press, Boca Raton 2000.

[4] Clar EJ, Her CP, Sturelle CG. Skin impedance and moisturization. J Soc Cosmet 1975; 26: 337-53.

[5] Kohli R, Archer WI, Roberts JMC, Cochran AJ, Wan Po AL. Impedance measurements for the non-invasive monitoring of skin hydration: a reassessment. Int J Pharm 1985; 26: 275-87. 
[6] Ollmar S, Nicander I. Information in multi-frequency measurement on intact skin. Innov Tech Biol Med 1995; 16: 745-51.

[7] Ollmar S. Methods of information extraction from impedance spectra of biological tissue, in particular skin and oral mucosa - a critical review and suggestions for the future. Bioelectrochemistry \& Bioenergetics 1998; 45: 157-60.

[8] Martinsen ØG, Grimnes S, Karlsen J. Electrical methods for skin moisture assessment. Skin Pharmacol 1995; 8: 237-45.

[9] Martinsen ØG, Grimnes S., Nilsen JK, Tronstad C, Jang W, Kim $\mathrm{H}$, Shin K, Naderi M, Thielmann F. Gravimetric method for in vivo calibration of skin hydration measurements. IEEE Trans Biomed Eng 2008: 55; 728-32.
[10] Martinsen ØG, Grimnes S, Henriksen I, Karlsen J. Measurement of the effect of topical liposome preparations by low frequency electrical susceptance. Innov Tech Biol Med 1996: 17; 217-22.

[11] Martinsen ØG, Grimnes S. Facts and myths about electrical measurement of stratum corneum hydration state. Dermatology 2001: $202 ; 87-89$.

[12] Grimnes S, Martinsen ØG. Bioimpedance and bioelectricity basics, 2. Ed. Academic Press, San Diego 2008.

[13] Martinsen ØG, Grimnes S, Sveen O. Dielectric properties of some keratinized tissues. Part 1: stratum corneum and nail in situ. Med Biol Eng Comput 1997; 35: 172-76.

(C) Martinsen and Grimnes; Licensee Bentham Open.

This is an open access article distributed under the terms of the Creative Commons Attribution License (http://creativecommons.org/licenses/by/2.5/), which permits unrestrictive use, distribution, and reproduction in any medium, provided the original work is properly cited. 